\title{
TLR9 Agonist IMO-2055
}

National Cancer Institute

\section{Source}

National Cancer Institute. TLR9 Agonist IMO-2055. NCI Thesaurus. Code C74083.

A synthetic olig onucleotide containing unmethylated $\mathrm{CpG}$ dinucleotides with potential immunopotentiating activity. Mimicking unmethylated $\mathrm{CpG}$ sequences in bacterial DNA, TLR9 agonist IMO-2055 binds to and activates intracellular Toll-like receptors (TLR) 9 in monocytes/macrophages, plasmacytoid dendritic cells (DCs) and B cells, initiating immune signaling pathways and activating B cells and DCs and inducing T-helper cell cytokine production. TLR9 is a member of the TLR family, which plays a fundamental role in pathogen recognition and activation of innate immunity. 